\title{
ENHANCING THE PRACTITIONER'S SENSE OF TIME, PLACE, AND PRACTICE: THE HISTORY OF CHINESE MEDICINE FOR PRACTITIONERS WORKSHOP
}

\author{
Marta Hanson and Andy Pham
}

\begin{abstract}
This article reproduces an exchange between academics and practitioners at the Sixth International Congress on Traditional Asian Medicine (ICTAM VI) meeting in Austin about how the history of Chinese medicine could be more meaningful, interesting, and valuable to clinicians. It provides a brief history of exchanges, the panel proposal, the abstracts of the panelists, an edited transcript of the conversation, and some concluding remarks from the participants. As more and more practitioners of Chinese medicine outside of China spend time in China, learn Chinese, become culturally and linguistically bilingual or multilingual, they seek more knowledge about what they practise than they can get in current publications in English or other European languages. The panel and this article are intended to encourage further exchange, conversations, and cooperation that will lead to new histories of Chinese medicine relevant for practitioners as much as for other academics.
\end{abstract}

\section{Introduction}

On 30 April 2006, the closing day of the Sixth International Congress on Traditional Asian Medicine (ICTAM VI), about 40 historians, anthropologists, practitioners, teachers, and students of Chinese medicine gathered for a workshop. They discussed issues concerning how the history of Chinese medicine could be more relevant and meaningful for practitioners. The idea for such a workshop germinated during a conversation with Vivienne Lo in August 2005, at the 11th International Conference on the History of Science in East Asia held in Munich. Further discussions there with Sabine Wilms on appropriate historical sources for clinical students and Nigel Wiseman on establishing translation standards in Chinese medicine solidified the concept.

The ICTAM VI workshop continued a discussion with practitioners and publishers in the field of Asian medicine that began five years ago in November 2000, in San Diego, California. The Pacific College of Oriental Medicine (PCOM) organises an Oriental Medicine 
Symposium every November.' In 2000, the Council of Oriental Medical Publishers (COMP) convened a meeting on the key issues they have encountered when translating Chinese medical texts into English. Six historians of Chinese medicine-Charlotte Furth, Xun Liu, Reiko Shinno, Sabine Wilms, Chia-feng Chang, and Marta Hanson-participated, along with about 25 other people. The principal members of COMP present that day were Dan Bensky, Nigel Wiseman, John O'Connor, Bob Felt, Zev Rosenberg, Miki Shima, and Andy Ellis.

The day before, many of the same people - historians, publishers, clinicians, translators, graduate students - participated in a one-day Chinese medical text-reading workshop held at the Department of History at the University of California at San Diego. This format of Chinese text-reading seminars had started at the Needham Research Institute (NRI) in England in the early 1990s. T. J. Hinrichs (now at Cornell University, Department of History) and Bridie Andrews (now at Bentley College, Department of History) brought the NRI text-reading seminar format to the United States when they organised the first Chinese medical text-reading workshop at Harvard University in May 1998. Ruth Rogaski (now at Vanderbilt University, Department of History) carried on the baton when she co-organised with TJ Hinrichs the second workshop held at Princeton University in May 2000. The UCSD text-reading workshop of November 2000 brought their model to the west coast to engage the unique convergence of people in the Chinese medical field at the Pacific Symposium with those in the region who work on Chinese medical history.

Such structured exchanges-collective readings of Chinese medical texts, discussions of translation issues for medical Chinese, and conversations on the teaching of Chinese medical history-have been rare among academics, publishers, practitioners, and students who are involved in Chinese medicine. We thought that it would be enlightening and possibly even inspirational to make these exchanges available to a wider audience. In this spirit, we have tried to recreate the discussion during the April 2006 ICTAM VI workshop by including the proposal, the abstracts of the panelists, an edited transcript, and several reflections by participants. ${ }^{2}$

\footnotetext{
' See 'Pacific Symposium' at www.pacificcollege.edu/index.html

${ }^{2}$ We thank Pierce Salguero for recording the conversation and transferring it to a disk for easier distribution. Andy Pham completed the entire transcription.
} 
This type of writing departs from the standard formats for an article published in academic and clinical journals. Three models have influenced the final format of this article and may be considered its predecessors. They similarly record conversations structured to facilitate communication across disciplines and encourage cross-fertilisation among all people engaged with Chinese medicine in the past and present.

First, the transcript of a conversation that took place in London in 1984 about 'Acupuncture in the West - a discussion between Ted Kaptchuk, Giovanni Maciocia, Felicity Moir and Peter Deadman' not only provided a precedent, but also helped place the exchanges of November 2000 and April 2006 in a longer history. ${ }^{3}$ Peter Deadman's participation in the November 2000 meeting and Felicity Moir's active participation at the April 2006 workshop further deepened the historical connection socially as well as intellectually. Secondly, the minutes of the November 2000 COMP meeting were made available on the Paradigm Publications website; they still give a good sense of the perennial translation issues in the Chinese medical field. ${ }^{4}$ Thirdly, the summary of a colloquium on different styles of needling held in February 2003 at the Tri-State College of Acupuncture in New York City offered a comparable model of how to preserve a collective conversation intended to promote cross-fertilisation through interdisciplinary interactions. ${ }^{5}$

\section{Panel proposal for ICTAM VI workshop}

Despite an increasing number of monographs on Chinese medical history, and even general histories of Chinese medicine, western practitioners of Chinese medicine would be hard pressed to find one book that satisfies their historical curiosity about the concepts they employ, the techniques they practise, and the medicines they dispense. From the earliest archeological evidence of diet, cauterisation,

\footnotetext{
${ }^{3}$ Deadman 1985.

4 The following url has the original minutes for the meeting of COMP at the Pacific Symposium, 6 November 2000: www.paradigm-pubs.com/resources/refs/ COMP-rpt2

5 Seem, Cassidy, Langevin, Lao, and Seem 2003. A medical anthropologist wrote her observations based on the video of the needling colloquium, see Emad 2003.
} 
medicinal herbs, movement, and nourishing life practices to the recent inventions of auricular therapy, electro-stimulation acupuncture, and five-phases psychology, hundreds of historical topics come to mind. Nevertheless, what topics and issues would be the most useful, of general interest, and meaningful for students of Chinese medicine as well as for seasoned practitioners? This workshop is intended to initiate a conversation on these issues by examining what Chinese medical history has to offer practice, presenting the current state of the historical literature, and discussing potential essay topics for a new history of Chinese medicine explicitly intended to meet the current needs, interests, and concerns of today's practitioners of Chinese medicine.

Panelists: Dan Bensky, Chip (Charles) Chace, Amy Hanks, Marta Hanson, Vivienne Lo, Shelley Ochs, Andy Pham, Volker Scheid.

Abstracts of participants:

Daniel Bensky, DO: A co-director of the Seattle Institute of Oriental Medicine, a medical editor at Eastland Press, and in private practice.

One of the challenges of this endeavour is how to help students learn more about what it means to be part of a tradition and how being part of the tradition is part and parcel of their clinical success and professional growth. I believe that studying the history of the medicine and how the interactions between society, culture, the environment, and the medicine have shaped East Asian medicine up to the present day is an integral part of the learning process.

Chip Chace, LAc: Practises Chinese medicine at Chautauqua Health, Boulder, Colorado.

The aspects of Chinese medical history of greatest interest to clinicians are likely to be those that have a direct bearing on how they think and practise. Readers are more likely to take an interest in the history of medicine in China if it is approached as a potential source of clinical information. Case records illustrating the practical application of representative formulas and ideas are an especially effective means of bringing historical material to life. Such an approach has the advantage of providing a longitudinal perspective over a broad swath of Chinese medical history. For instance, the conceptual development of Warm Disease theory is readily traced from case records reaching at least as far back as the Jin-Yuan period up through the present. 
Marta Hanson, PhD: Assistant Professor, Department of the History of Medicine, Johns Hopkins University, Baltimore, Maryland.

I am most interested in considering what a history of Chinese medicine written for practitioners should cover to bridge the realms of history and practice. Hybridity, pluralism, identity formation, innovation, regionalism, multiplicity, gender, and transformation all have informed the work of various historians and anthropologists of Chinese medicine. What questions and concerns of those practising in the field, however, are not being met in the current literature on the history of medicine? Conversely, how would addressing these concerns and answering their questions enrich the field of Chinese medical history? Is there interest in a new historical survey of Chinese medicine organised around the key physicians, their practises, and publications, or one structured according to clinical disciplines such as pharmaceutics (Unschuld 1986), acupuncture-moxibustion (Yamada, Lu and Needham, Felt and Birch, Lo), obstetrics-gynecology (Furth), and pediatrics (Hsiung)? Toward this end, I survey the current books that provide an overview of Chinese medical history and bring several possibilities to the table to discuss for a new synthesis intended for the increasing numbers of practitioners of Chinese and Oriental Medicine. Amy Hanks, MS, LAc: An instructor at the American College of Traditional Chinese Medicine, San Francisco, teaching the history of Chinese medicine and Medical Chinese. She maintains a private practise in San Francisco.

In the west, students often enter acupuncture programmes with very little linguistic, cultural, or historical knowledge of Asia. Acupuncture colleges that include a course on the history of medicine in their curriculum often allow only 15 to 30 hours for the topic and may require that the course covers the history of both Chinese and western medicine, as well as introduce other major healing modalities from around the globe. These facts immediately present the teaching faculty with several challenges. First, the presentation of the history of Chinese medicine must be woven into the broad outline of general Chinese history, so that students develop a rudimentary understanding of the historical context in which various aspects of Chinese medicine emerged. Secondly, the material must be presented in a very limited period. There is also a third pressure of ensuring that students achieve a basic historical fluency vis-à-vis the major personages and texts of Chinese medicine. One final challenge in making the history of Chinese medicine relevant to the 
female-dominant student bodies of acupuncture colleges in the west, is addressing the gender inequality of the historical record that allows us to examine, primarily, only the ideas and contributions of male healers.

TJ Hinrichs, PhD: Department of History, Cornell University, Ithaca, New York. ${ }^{6}$

Historians take issue with some of the romantic generalisations made by practitioners about Chinese medical history. Why do practitioners find history meaningful, and what can historians offer them? Does it matter whether 'acupuncture' has a history of five decades, several centuries, two millennia, or five? Does it matter whether Chinese cosmology is 'Daoist'? Such interest in or construction of history is not new to modern practitioners. To the extent that it informs practice and identity, it is worth thinking about how it has operated in the past, and how it is being used today.

Vivienne Lo, PhD, MBAcC: Lecturer, The Wellcome Trust Centre for the History of Medicine, University College London.

Citing texts dating to a legendary Yellow Emperor, practitioners frequently call on many thousands of years of empirical history in order to justify their modern practice. But, even if we read the received classical texts carefully and appreciate the diversity of practice they represent, can we believe that they were the basis of widespread practice throughout the millennia? This contribution is a reflection on a life in practice and 15 years of reading, and teaching about, Chinese medical manuscripts. What were practitioners really doing at different times, and what does it matter to modern practice?

Shelley Ochs, LAc: Practises at the Bluegrass Chinese Medicine Clinic and translates Chinese medical texts in Louisville, Kentucky.

In my own experience as a practitioner and as a bilingual student of Chinese medicine, I have found that an understanding of the history of medicine in China has a direct impact upon how practitioners define both 'the tradition of Chinese medicine' and our relationship to it. When the historical reality of the plurality of medical practices and ideas in China is accepted, we can no longer naively believe that the body of knowledge presented as 'Chinese medicine'

${ }_{6} \mathrm{TJ}$ Hinrichs was unable to attend. We included her abstract because it raised relevant issues. 
in our educational programmes accurately reflects a single, historical 'tradition'. The recognition of plurality opens up possibilities for including ideas and practices from inside and outside China, because they are no longer forced to fit into one model of medical practice. It also allows greater room for reflection and interpretation of medical literature without the assumption of coherence and continuity across time and space.

Andy Pham: a senior student of Chinese medicine in the San Francisco Bay area and a graduate of the University of California at Berkeley (BA 2003 in Interdisciplinary Studies, emphasis on social and cultural theory with a concentration in Chinese history and Chinese philosophy).

There is a disassociation between the required subjects that students must learn, both before and after entering Traditional Chinese Medicine (TCM) schools, and the subjects that are actually relevant to Chinese medicine. Rather than the biosciences and biomedical concepts, the ancient Chinese philosophical ideas and historical schools are critical to an appreciation of Chinese medicine in its cultural originality. Despite this, the biomedical sciences continue to exert increasing influence on the curriculum of TCM schools, representing the hegemonic position of the biomedical model. To reverse this trend, a counter-hegemonic response is suggested whereby Chinese history and philosophy are promoted in the TCM schools, through requiring prerequisites in these subjects, allowing students to relate better to classes in Chinese medical history and philosophy. Ultimately, this academic background would facilitate the engagement with clinical Chinese medicine as 'historical medicine' and gradually foster a demographic shift in the TCM student profile, evolving from the propensity as a 'mechanic' clinician towards a developing 'intellectual' physician, borrowing Unschuld's characterisation. In this orientation, students begin to venerate the scholar physicians, classical and modern, who comprise the Chinese medical tradition.

Volker Scheid, PhD, FRCHM, MBAcC: Academic Director of the European Institute of Oriental Medicine (EIOM) and a practitioner of Chinese medicine in London.

I am an anthropologist/historian as well as a Chinese medicine practitioner, and have taught Chinese medicine for over ten years to a variety of audiences. I will reflect on my personal experiences of using history as a method for deepening clinical skills, and, conversely, courses on clinical medicine as a vehicle for teaching history to clinicians. 


\section{Transcript of discussion}

Note: In the following dialogue, the views of conference presenters and attendees in the audience, identified as such, are faithfully summarised, while the panelists' responses and positions are transcribed with some editing to avoid repetition. The panelists' names are in bold. Marta Hanson first distributed two bibliographies of books in English and Chinese on the history of Chinese medicine. She discussed the range of themes as well as different ways of organising historical surveys: chronologically, thematically, or according to a discipline such as acupuncture-moxibustion, materia medica, gynaecology, or paediatrics. The original bibliography of historical surveys in English has been updated and is available at the end of this article. Amy Hanks: I brought a list; it's not comprehensive, it's a list of the major readings I use in my course on the history of healing at the American College of Traditional Chinese Medicine in San Francisco. I'm going to start off by telling you what the constraints are that make this list so abbreviated. I teach a 33-hour course, and only half of that time is devoted to the history of Chinese medicine, so really only 15 to 18 hours. The list that I have is really a reflection of things that I've pieced together. I'm really glad that this conversation is taking place, because I've been frustrated by not having a text, and the students have been frustrated too. So, the readings that you'll see here are really either complementing or supplementing my lectures. In particular, Subhuti Dharmananda, he's a practitioner who writes fairly good articles on history, very succinct, and at the end, talks about how the person he's writing about, like Sun Simiao, is relevant to modern practice, what formulas they created that we're studying, etc. Or his article about Hua Tuo, that's why we have these points right along the spine called the 'Hua Tuo jiaji xue' (Hua Tuo's paravertebral points). ${ }^{7}$ So, it's very applicable for the students, because they're already learning these kinds of things. With the other sources, you'll see it's literally cutting-and-pasting paragraphs out of books, in part because I wanted the students to have at least a paragraph on most of the famous physicians to read, in addition to my notes.

7 The articles referred to appear at www.itmonline.org/arts/sunsimiao.htm and www.itmonline.org/arts/huatuo.htm. Other classical physicians are described at www.itmonline.org/docs/famous.htm 
Dan Bensky: Maybe my contribution would be more global rather than particular. I teach a class, also about 16 hours, on the history of Chinese medicine. My very clear bias, I think, is that the whole purpose of teaching people history is about what does it mean to do traditional medicine in the twenty-first century. Personally, the answer is, so they know that in Chinese medicine, there's the text, there's the tradition, and then there's us. It's a text-based tradition that we learn. And so, you have to put the text in context, the tradition in context, and then you have to do it in a way that the students feel that it's not something in the past, but something that they can contribute to also, as a part of who they are. In our course, we do a kind of chronological approach, but mostly trying to connect the kind of philosophical, social, and economic currents in the different periods with the type of medicine practised in that period. So that they can look at a formula and say, 'Oh, that must be a Han-dynasty formula, that looks like a Song-dynasty formula', and then why those things might be important to them when thinking which kind of formula they want to use for a particular kind of patient. We don't use too many readings outside, like the stuff Amy would give them. I would just talk about them. The readings we do read are actually medical texts, look at the Shanghan lun (Treatise on Cold Damage) and how that reflects Han-dynasty cosmology and thought, look at the things from Sijunzi tang (Four Gentleman's Decoction), the Song-dynasty pharmaceutical industries, etc. We can go on like that.

Amy Hanks: One of the challenges that we probably both face is that our students come to us with no background in Chinese history, with the exception of a few people. So within our 15-hour courses, we not only have to try and cover the entire expanse of Chinese medicine, but also give them a framework of Chinese history to fit it all into.

Dan Bensky: The things you have to memorise outside of class give the context or background for the rest. The names and dates of the dynasties, what part of China grows wheat, what part grows rice, what part has mostly 'robust' people, that kind of regionalism. I think that is something they just have to memorise; it's like you have to memorise herbs, you have to memorise points. You have to memorise this stuff, because otherwise you can't be part of the tradition, unless you have certain kinds of backgrounds. You don't know your Han from your Tang, then you really can't do the work, you can't be part of the tradition. It's not very hard. 
Adam Margolis, an acupuncturist working in an integrative hospital setting, related how he found the most relevant approach in TCM history class was biographical. With time constraints, starting from biographies of formulators was the clearest way to orient oneself within a huge history. He wonders how much other instructors may do this.

Amy Hanks: I don't rely on it exclusively, but the backbone of my course is Unschuld's $A$ History of Ideas. ${ }^{8}$ There's many people in that book, so I have to pick and choose. I think that's why I do rely on Subhuti Dharmananda's articles so much, because he does focus on particular physicians.

Vivienne Lo: A lot of the people who are here contributed to a dictionary of medical biographies that includes 33 Chinese practitioners in very short, sharp, two-page summaries. (Dialogue among some of the contributors ensued).

Felicity Moir, an ICTAM panel moderator, then asked about the details of this dictionary.

Vivienne Lo: This is the Dictionary of Medical Biography, to be published by Greenwood Press next year. It's edited by Bill and Helen Bynum. I've edited the Chinese and Korean sections and written the introductory essay. ${ }^{9}$

Felicity Moir then asked Adam Margolis why he found it so important as a student to focus on the biographies, rather than the broader history. He replied that as a clinician not focused on history, he found it more practical to learn about the formulators, and the context in which they formed their ideas. Although it would be nice to learn a year of Chinese history, Adam stated that clinical training does not afford that luxury.

Zev Rosenberg, an ICTAM presenter, responded to Adam's belief that history and clinical education are separate. As an instructor, he does not see medical history as divided from teaching medicine. Using Bensky's Formulas and Strategies, ${ }^{10}$ he reviewed the classical physicians' descriptions of the formulas they devised. Appreciating the historical and philosophical ideas that influenced them allows one to understand the code embodied in their prescriptions. Understanding the logic of this code allows one to adapt and possibly develop these

\footnotetext{
8 Unschuld 1985.

9 Bynum and Bynum 2007.

10 Bensky and Barolet 1990.
} 
prescriptions further, rather than just mimic how they appear in textbooks. He reiterated the value he places on medical history as an instructor, but doesn't think that the schools 'get it yet'. He conveyed how students feel a lot of pressure from biomedical classes and sometimes see herbal training as a distraction, when it is so essential.

Marta Hanson: What I'm hearing from you, Adam, Amy, and Dan is that what we don't yet have is a survey that has the clinical aspects integrated into it.

Volker Scheid: I want to talk about the problem that Zev raised. If you want to teach - from my experience of teaching practitioners and as somebody who really likes history for history's sake - if you want to touch practitioners, you have to make it clinically relevant, for the reason that practitioners have different interests and limited time. So they cannot, even if they wanted to. I think if you want to get to practitioners, one strategy is through the teachers, and I think the teachers need a lot better educating in the history of Chinese medicine. I think most teachers don't really understand enough about the history of Chinese medicine. Texts like Unschuld's give you a broad outline, but they wouldn't do the job that you want to have done. ${ }^{11}$ Like there's no Zhongyi gejia xueshuo in there. ${ }^{12}$ So where would the teachers who don't speak Chinese (and many of the European teachers don't speak Chinese) get their information from? I think one of the jobs would be a resource, not necessarily for students, but a primary resource for teachers. So teachers could get their information and be able to place their clinical teaching into a historical context, to achieve what Zev suggests. I think it would have to go beyond what you're saying. Not just explicating where a particular doctor stands, but actually you can also take any formula (and explain it). The formula has a history. Or acupuncture points, or acupuncture styles; they all have a history. I think, as a teacher, if I can in my clinical teaching make that history come alive, that's what speaks to students.

Chip Chace: Just following up on this idea of making it clinically relevant. I'm really the target audience of this conversation, at least a postgraduate target audience. And as someone who, every so often, does speak to fellow colleagues, namely people who are out of

11 Unschuld 1986.

12 'Doctrines of the Lineages of Learning of Chinese Medicine'; RenYingqiu 1980. 
acupuncture school and practising. My contribution to this conversation is to encourage us to think in terms of the case record as a medium for conveying a lot of this information. The case record gives us all of that prescription history, it gives us personal history, it gives us a milieu of the time. What does a case record from the Ming dynasty look like, as opposed to a case history from the Qing dynasty? Even within one time period, different people's case histories. I'm hesitant to even mention the Wenbing (Warm Disease) tradition among you two, Marta and Volker. But, I certainly look at those case records that everybody studied, and initially, they're impenetrable. What were they thinking, that they were just studying these all the time? And that moment to me, as somebody who's trying to communicate that to other people, that's a teaching moment for me. In terms of saying, 'Look, they approached things differently, they had different assumptions about what you knew as a physician, even what you knew as a student.' A lot of the background information that can be really painful to accumulate, in the course of laying out a foundation, can be plugged in, in little, pretty bite-sized bits and pieces. As you say, well, OK, for us to understand this case record, we have to understand this about what was going on at the time, or how certainly, this notion of 'currents of ideas', see, this case record is really an extension of this person's ideas. Not just who came before, but also how that case influenced subsequent case records. Of course, I have a bias: I like history, and I like case records too. But for me, it's been a very juicy way of picking up medical history, because if I don't get what this case record is telling me or why that should be important, it makes all of the formula information that Zev was talking about, it just takes it one more step further.

Rey Tiquia, an ICTAM presenter, emphasised the need to let practitioners 'speak' for themselves. There is an inherent challenge, in that the history of Chinese medicine is very, very long. In 'speaking for themselves', aspects of oral history take on significance. He researched the lives of two Chinese herbalists in Melbourne, relying on interviews with their descendents. Chinese medicine was very marginalised in 1870s Australia. He found that one of the herbalists hired a Queen's Council to help reverse the court decision against him. Through archival documents and interviewing, he was able to reconstruct their lives. It gives the history of practice of Chinese medicine a human face. 
Marta Hanson: What I like about your comment there, is of the 33 biographies in the Dictionary of Medical Biography, they pretty much end at the Republican period. And what you're really arguing is looking at more recent biographies of people, and more complicated histories of the Chinese diaspora in Australia, which I think is a really interesting, a really relevant point to make about its transmission to other parts of the world. Making it personalised in a biography. I think biography is obviously a strong approach to take, integrating the case studies, the history of their lineage, where they came from, and such things.

Shelley Ochs: I think that in school you sort of get a structure that you later hang other things on, and so I think it's very important. One kind of example of that structure for me is that at school we learned that TCM is zangfu (visceral systems) diagnosis. That is what's unique about Chinese medicine. The way this is described in the literature, for example Volker Scheid's work, is really very much what we learned. ${ }^{13}$ We learn that when we are doing Chinese medicine, it's holistic, it's individual, and so on. It doesn't really matter whether the aetiology is due to drugs they're taking, or other reasons. You just look at everything that's going on, you come up with your zangfu diagnosis, and then you come up with a formula and herbs. We were taught that this is Chinese medicine. 'Bianzheng lunzhi' (pattern differentiation and treatment determination), you could call it, or 'Li fa fang yao' (pattern, method, formula, drugs), is what it is. On the other hand, in our clinical education, already you have different things, because you get to see real doctors and how they practise. Even though they felt, I think, often limited by working in an environment where Chinese medical practice was defined in a particular way. So, for example, as a student, one of the things I wondered about was, how do I incorporate herbs from other traditions? How can I incorporate local herbs? Because I thought they all have to fit into this strict structure. What are their functions in TCM terms, what channels do they enter, and what are their flavours and so on? But once, at a certain point, I realised that that's not the history of the herbal tradition, that that's not the whole story, that people have used other rubrics to think about how to use herbs, then that opens it up. And then, when you understand that the encyclopedias, even Li Shizhen's work, were compiled by going around

13 Scheid 2002. 
and collecting herbs and that there was this process of 'caoyao' (raw medicinals) being incorporated into 'zhongyao' (Chinese medicinals). ${ }^{14}$ My point is just that I think it affects your directions of learning and it affects your directions of development as a practitioner. I think it's important to have a structure. Of course you can't just say there's ideas a, b, c, and d, take your pick. And people have to have competency exams and so on and so forth, but I think to have some kind of structure that's flexible enough and broad enough to encompass more plurality would be a big improvement over what we're getting now.

Rey Tiquia conceded that reading the long history of Chinese medicine can be a 'pretty boring exercise', but with persistence, one can find differences. So don't be deterred by the boring aspect. You have to look. Finding slightly different perspectives from numerous commentators may reveal different ideas about the same person. If you take the different accounts of Zhang Zhongji as an historical example, then oral histories can supplement and enrich the recorded accounts. ${ }^{15}$

Marta Hanson: I think you're developing on Shelley's point, that it gives you a sense as a clinician of a broader realm of possibility, of choices. I think, building up on Dan's point too, of the practitioner as feeling a sense of contributing to a larger tradition, that they also have a place in that history, and that they're not just repeating and blindly following the past, but are engaging with the present and making their own contributions and their own decisions, within that consciousness of that larger history. I think that's an important thread too that's coming up in this conversation.

Simcha Gottlieb, an ICTAM panel moderator, emphasised how the dimension of time influences the clinical encounter. The patient has a history, prognosis, and expectation. A deeper understanding of the history allows one to be more present in the moment, in some paradoxical sense. Any idea is part of a continuum, marks a moment in time, but is also part of a 'flow'. Cultivating this sense enhances and facilitates students' experience, helps them not feel stuck in time.

14 Reference to the late sixteenth-century Bencao gangmu (Systematic Materia Medica, 1596) by Li Shizhen (1518-93).

15 Reference to the author also known as Zhang Ji (150-219 CE) of the Treatise on Cold Damage and Miscellaneous Disorders (Shanghan zabing lun), and other late-Han medical texts. 
It gives them a sense of the dynamic quality of theoretical concepts, rather than just learning static ideas.

Zev Rosenberg asserted that a challenge one has to contend with, in teaching TCM in this culture, is a bias against history. There is a bias towards the modern, the latest developments, characteristic of biomedicine, which often views knowledge from even five or ten years ago to be obsolete. The reliance on ideas from thousands of years ago, which is characteristic of TCM, and respect for this tradition is something that must be taught to students. For most of them, it is rather unheard of within their cultural background.

Stephen Boyanton, an ICTAM presenter, agreed that 'currents of learning' or xuepai, and individual biographies do seem like the most effective ways to get at the clinically perceived, relevant parts of Chinese medical history. Other parts of Chinese culture such as religious and philosophical ideas are also important. They are still circulating in the public, but are often misrepresented by practitioners. As anyone familiar with the history of Chinese religions knows, the popular imagination of these religious issues is 'woefully far removed' from the reality of what it was.

Dan Bensky: Actually, one of the things I've been thinking of in our own school is when to do this course. And we've tried different ways: one way that I think worked really well, related to your issue, is that we do it in the very first semester as a kind of 'vaccination' against, uh, can we use 'vaccination' in Chinese medicine?

(Laughter from audience). Or, variolation? 'Inoculation' is the more traditional Chinese. But, one of the things some students do is they want to conflate themselves with something that has nothing to do with them (perhaps the medical ideas they are learning with the popular religious perceptions they may have). Another thing we do for that, along with the history, is we have them see patients right away. If they don't want to hear people talk about their bodily functions all day, they quit. But it's this inoculation, so that when they get to start talking with people that 'I do Chinese medicine. Oh, well, you must then, like, flow with the Dao, and like...' 'No, no, that's not it', they have some basic knowledge about, you know, 'I don't know that much about it, but I know that's not it.' I think in terms of weighing a book, you have to think about when the book would be used in the course. Is it going to be something that would be for teachers, something that could be used for advanced students, and there would have to be some way that you could use it for 
people for whom this is their very first class in school. I think you might want to think about how to do something that is applicable to all those things. And to me, another inoculation, and I have to disagree with one of our previous conferences, I think that doing standard textbook translation from China into English is a disastrous idea. What we need, and what they may or may not need, are two different things. I think that part of the inoculation, of having the history background, is against that also.

Amy Hanks: We face the same issue, exactly where in our curriculum should this course go? It was put at the beginning, and that's probably a good place for it, to explode a lot of the preconceptions that our students come in with. But every once in a while, some students who take it later in their schedule relate to me that they feel they know so much more about what they're studying now. They're glad they took the course later, because they have already used herbal formulas, from Sun Simiao and the Jin-Yuan reformers. If they had taken the course at the beginning, it wouldn't have made any sense to them then.

Marta Hanson: Maybe we're talking about two different types of history courses, one at the beginning, and one later?

Dan Bensky: We're not going to get two different types of courses (laughter). I think the schools are going to do whatever they think, but I think you're going to have to come up with a textbook that the different schools could use regardless if they wanted to do it first or if they wanted to use it in the third year. That, I think, is going to be the necessary flexibility of the book.

Vivienne Lo: Mostly, what I always wanted to convey to people, what I wanted to express, is the idea of change, and the tensions that exist between writing chronologically and writing thematically. I think there are some very good ideas about how to structure a case histories book coming out in this discussion. A chapter, which focuses on case histories, a chapter that looks at biographies, with original texts to back it up would be very good. But within that, within each section, you should have something chronological to address this tension and the issues. One way to do such a textbook would be a beginning survey of the history of Chinese medicine, and organise the rest as thematic chapters.

Marta Hanson: Your acupuncture exhibition does that, very well. Vivienne Lo: What I learned really from that was to think more thematically, that it's easier than thinking chronologically when you're 
talking to people outside the history field. There's too much material and the histories are too long and not meaningful unless you have some impression of the sociopolitical and cultural contexts of each period. It's very hard to present 2,000 years. I again confronted this issue when asked to cover the last 2,000 years in an undergraduate acupuncture course, and about what approaches (to take). Clearly, later in the clinical training is easier, once they have the terms to hang onto and the framework we're trying to offer them. So starting with case histories, starting with biographies, is easier than starting with the whole thing. Then, specifically the subject that for me has always been most interesting, is the relationship of the manuscript tradition to the received texts that were edited in the Song and transmitted in book form. To make it relevant, it's interesting to focus on how different the kinds of treatments are that you find; the kinds of ideas that you find in the manuscript tradition are very different from the received texts that become part of a postSong orthodoxy. For example, if you're looking at the Dunhuang texts about treatment, they look more like manuals. What you find is that nobody used acupuncture points. Nobody used acupuncture; they used moxibustion. So, to what extent have these received texts actually distorted our view of what happened in earlier times?

Marta Hanson: My students liked the week I focused on the Dunhuang manuscripts and your articles. ${ }^{16}$ They understand the idea that manuscripts opened up a window that's no longer preserved in the edited printed texts. They really, don't you agree, just get it.

Vivienne Lo: It's very simple. And it also comments on the difference between what people do at the point of practice and what they read in these texts. A lot of the time, you read this stuff in the texts and then come to our practice, and you know what we're doing is not like what is said in the texts, and feel insecure because of that. There are important issues in these manuscripts for research as well.

Will Morris, President of the Academy of Oriental Medicine at Austin, asked about the 'becoming' of the physician, and how one is identified as such within a culture? How do they gain authority through codes of ethics? The social context of being a physician is as important as the knowledge and skills that they gain.

${ }^{16}$ Lo and Cullen 2005. 
Marta Hanson: That's something that biographies really lend themselves well to; we're talking about the range of healers, of which literati physician represented one type of a wide range of healers.

Felicity Moir expressed her interest in the updating of biographies. Stories of current practitioners are also useful. They offer personal reflections, their sources, which are not always in the published texts. In essence, they engage in a reflexive process of self-reflection on their practice. Maybe this could be an ongoing feature in journals? Vivienne Lo: Since a lot of you are here, why don't you submit your thoughts to Asian Medicine? We want personal statements of your schools, your thoughts, how Jack Worsley influenced you, or didn't. ${ }^{17}$ I want all of you to write and submit it to us.

Dan Bensky: You may have to explain to some people about the journal, they may not all be up on it.

Marta Hanson: Explain what you would look for, develop on it more.

Vivienne Lo: Asian Medicine is the new journal of IASTAM now in its second year. I suppose practitioners beginning to write not about the theories of what they do, but their own biographies, their experiences, their reflections on their practice; rather than prescriptive, be descriptive. I think that's essential, describe who you are and what you do, and we'll publish it. Without saying this is what you must do. A history of who you work with, where you work. We're interested. And the more the better, so that it's not too biased to one particular kind of submission.

Volker Scheid: I just want to say something that's just coming up to me in the course of this conversation. I think they're two different things. Chinese medicine is a history, like, Chinese medicine is history. And, that's very different from biomedicine. Well, I think so. Marta Hanson: Or how biomedicine constructs itself, presents itself in a way.

Volker Scheid: Well, that's what I mean. No, but Chinese medicine traditionally, well, at least how I read all these old physicians and modern physicians. They talk about them. They're very aware of their place in that history. And as always being in that history and working within that history, I think that position is very different

17 Reference to J. R. Worsley, founder of The College of Traditional Chinese Acupuncture (UK), The Traditional Acupuncture Institute (USA), and of the 'Five Elements' tradition. 
from what Zev said before about a biomedical physician, for whom what happened yesterday is totally irrelevant. But, I think that once you construct that history of Chinese medicine, already you're stepping, in a certain way, out of that process. If you're teaching a course about the history of Chinese medicine, that is also something very modern and very western, in a certain sense, rather than being within that flow of history. I think we need to be very aware of that. I can only relate that to my experience. I don't teach a course on the history of Chinese medicine, but sometimes, I do a day on the history of modern acupuncture, or something like that. People take that as the history, and then they forget about it. Which is very different than if I teach, like formulas, where I situate each formula, each doctor, the cases, and myself within modern history, and try to get the students to be part of that history. I think these are two totally different ways of relating oneself to that tradition. I think it's really important (i.e., to be aware of the difference).

Felicity Moir asked whether what he means is like embedding the history in the whole teaching, learning, and clinical work.

Volker Scheid: Make yourself ask, what is the goal? Do you want to teach a history course, so that people have facts available afterwards and they can say in the Song dynasty, that happened, and in the Qing dynasty, that happened, and Sun Simiao lived at that time and he had those ideas and he used those formulas? Or, no, am I a person that stands within that tradition, who owns it, and is part of it? If that's the goal, you want to enable them, and I think these are two very different goals. They are interconnected, but they're also different.

Vivienne Lo: How do you do it? I mean, how do you do that? You say, you teach the teachers, but practically, how do you do that? I mean, for those people working in schools? How much do you need to know in order to make those formulas relevant?

Volker Scheid: A lot. (Laughter from the audience).

Vivienne Lo: Volker, you're in a privileged position, you know. I'm just interested in whether it's a practical solution. I think it's the best solution myself, but I don't know if it is practical.

Volker Scheid: If you ask me very concretely, it's like if you look at all these people you want to write biographies about, like Ye Tianshi, or Sun Simiao, or Zhang Jiebin, or Zhang Xichun, or even, you know, modern physicians like Qin Bowei or Cheng Menxue. Those physicians are our ideals, so we have to do what they did. They 
read medical texts all the time; they read history all the time; they knew about everything. If those practices are our ideals, if they are the people we want to follow, then we have to follow what they did. Vivienne Lo: So practically, you cultivate that in MA courses for teachers, is that what you mean?

Volker Scheid: Yes, that would be the situation where we are. When we cannot demand that from our undergraduates, then we should demand it from our teachers. But, they should be very sure, when they teach, that they know exactly where it comes from; the teachers at least should have a historical understanding.

Marta Hanson: Because knowing where it comes from, what you're saying, is that it is most important when it's about work from which a practitioner can form an identity, something they're coming out of. It personalises it.

Dan Bensky: I think, from my perspective, this may be a little far a field. Unusual for me. Part of the issue has to do with what Shelley was talking about earlier. If you teach people one particular approach, then they become very ossified in their understanding of things and they end up doing things that are insane. They'll see a patient in clinic who has asthma. And, they'll try to fit the patient into one of six categories or eight categories of asthma. So part of the process of teaching undergraduates is to expose them to a bunch of different ways of utilising the different systems of East Asian medicine. Each one of those systems reflects upon the other one; in this way they actually will learn any particular one better, if they learn two or three at a time, from different teachers who take ownership of their particular style, without rejecting other people. 'This is what I do, other people are OK.' I think history is part of that. You have these different streams, you come from different places, you have different ways of doing things. And so, the teachers have to model that for the students. Not necessarily model as talking about history, but you know, you have the person who does Nanjing style acupuncture, teach the students the Nanjing (Canon of Problems), right? And then when we do Shanghan lun (Treatise on Cold Damage) stuff, we think about, what about this patient, we might use this way of looking at things, different types of commentators, they start thinking about how they fit into the tradition. But I think if you teach, whatever the way it is, if you teach one way of doing the medicine, then the history can't really inform it. There are too many ways. It doesn't make sense to the students. 
Vivienne Lo: A more natural disposition is one of confusion. I enjoy being confused, but most people don't. (Laughter from the audience).

Dan Bensky: Well, if you don't enjoy being confused, you'll have a hard time doing Chinese medicine. (More laughter). I mean, I understand it's a tension, but I think, to me, the history is part of that. If this is the way it is, and then you study history, there will be parts of the history that don't fit. And so, I think that has to be part of the whole model.

Brenda Loew, an ICTAM presenter, stipulated that the challenge of teaching is in a culture that expects unified theory and reality, one right way. They forget that truths change over time.

Dan Bensky: Yes, but again, if they're in clinic very long, it's in their face: that didn't work. Right, my way of understanding this patient is ridiculous. Right? I mean, I find this everyday in my clinic. So, I think the schools have to take this challenge, that if the goal is to turn out people who are part of the tradition, then they have to be confused at one point to get to a place where they feel confident. Vivienne Lo: But at which point do they have to be confused? Dan Bensky: Well, they have to be confused when they start. I think they will find their own, you know, relative lack of confusion. So, when you do the history, you don't want a standard thing because that will end up with a kind of retrospective look at how history ended up with us. If it's for students who are going to be practitioners, the context has to be, when I see the patient in the clinic or I think about what to do, how does this impact that? How does it have an impact when it doesn't work, where do I go, and how do I think about it? If the history has an impact on that, then they'll be interested in it; if it doesn't, then they won't be.

Vivienne Lo: How does it work in practice, in a book?

Dan Bensky: I don't know. That seems, I would think, and Chip has done some work on this, the best kind of case histories, for this kind of thing, are the case histories where someone has screwed up. There's a whole literature of case histories for incorrect treatment. And those cases, I think, are the most interesting, particularly when it's the person himself who did the incorrect treatment and then figured out what to do. And there's a long tradition of this, which goes up to the present time. I think the thing that I'm thinking about is commonly dealt with. A person approaches things from this style, it doesn't work, they sit back and think, 'Oh, I should try this style', here's 
why, and they get some more beneficial results. So I think that is, off the top of my head, that's the kind of case that would help do this. Volker Scheid: And another thing I'm just thinking of, part of the biography also has to be a human biography that creates ideals, but I think it's also as important to demystify those people. Not just build them up as these fantastic physicians, you know, Ye Tianshi was also somebody who was human; I mean these guys were also into money, power, and status. They were real human beings. And it's also liberating, to see that they are not any better than us; they are ideals, but they are also human.

Jane Wilson, an ICTAM panelist, said that she 'would like to leave the history teaching to the historians'. Referring to concepts of time and dynamism, she contrasted western medicine and western science philosophies. Western science is perhaps a better match for Chinese medicine because it's moving, changing, dynamic in its theoretical outlook. She added that students can gain the principles of history at any time, assuming they took a class on the subject in the first semester. She related how third-year students then ask her for advice as a clinical supervisor, and she assured them that they're now in that history, and they then feel somewhat empowered to make clinical choices.

Vivienne Lo: You see, Volker, she doesn't want to teach history. Marta Hanson: Well, I do think it's up to the historians and those who find history valuable to make it relevant for clinicians. That's why we're having this conversation. I just want to put on the table that I have a view of history that's not of something about the past, but it's more conceptual, about opening up realms of possibilities for thinking in the present. I think that's where I'd like to go with the way we present Chinese history for clinicians, especially with the point that Shelley made about her frustrations, in terms of feeling ossified, in a sense, and trying to find a wider realm of possibility. I think this is definitely Dan's point as well. So I want to present the history of Chinese medicine-because that's how I think of history and that's the way I try to teach it to my students - in terms of breaking them out of the biomedical way of looking at the body, and looking at multiple realms of possibility of experience.

Zev Rosenberg said in response that Chinese medicine is heterogeneous. It would be useful to systematise the approaches. Pulse-taking has multiple approaches. At his school, there is often a lack of interreliability on pulse diagnosis: clinical supervisors do not agree on 
what type of pulse is felt. Students feel it is too subjective and do not rely on it as much, which is a major loss. We must get beyond the hierarchical idea that TCM is real Chinese medicine; it was an expression, suitable for a time and place. The challenge now is to find an expression suitable in the west, without 'biomedicalising' it.

Brenda Loew referred to two books that may challenge the idea, implicitly held by some attendees, that biomedicine represents a unified model. ${ }^{18}$

Stephen Boyanton cited the chapter in Volker Scheid's book where the $\mathrm{PhD}$ candidate traced a clinical condition through the corpus of classical Chinese medicine, searching for 'new' ideas and inspiration from the past tradition. It is very powerful if you can incorporate history into other aspects of clinical training. In formulas class, knowing who made them, why do they have the structure they have? In the long term, this helps remember the formulas, even if their uses now may be different from their original functions. But, certain basic facts should be known, or it looks bad for the profession when people don't know, roughly at least, when Sun Simiao (581-682) lived or how far apart he was from Ye Tianshi (1667-1746). (Laughter and replies about their spirits living on).

Amy Hanks: This is something that students actually brought up to me, after I gave my class the first time. At the very end, one of the students raised her hand and asked, 'Well, what about the women?'. The truth is, I don't know if my school is representative of all TCM schools, but we're a good 75 per cent women. Most of the things we've talked about so far, biographies, case studies, etc., for the most part, do not include women.

Marta Hanson: I spend three weeks teaching [chapters from] Charlotte Furth['s book]. ${ }^{19}$ And then Sabine Wilms has a new book coming out on women's recipes in the Tang dynasty. ${ }^{20}$

Amy Hanks: But in terms of tangible information, it's particularly challenging in the earlier periods, very challenging. Moving beyond just gynaecology, with women more as the subject, rather than the object of inquiry.

Marta Hanson: I bring up Furth because her entire last chapter is on women healers.

\footnotetext{
18 Payer 1996 [1986]; Wallace 1996.

19 Furth 1999.

20 Wilms 2006.
} 
Shelley Ochs: It's interesting how we're replicating that today, in some ways. Because if you look at, for example, a Redwing Books catalogue, or you look at the books that are published for professionals about Chinese medicine, you find that, despite the fact that across the country there are 16,000 of us in the US and there are far more women than men, there's a very small number of women who publish. There are more women who teach CEU seminars and so on, but there are a very few women who publish. And that's a really interesting thing, since it is especially disproportionate given that there are more women than men in the field. So it would be interesting to think about why that happens, why women are not writing. I mean, obviously there are social reasons too, child rearing and so on, but why are women pursuing practice, more than pursuing teaching or writing? It's just an obvious phenomena.

Sylvia Schroer, an ICTAM presenter, recalled that at Leamington $\mathrm{Spa},{ }^{21}$ she felt she had no exposure to history. She recounted a recent class she attended at the University of Westminster on complementary therapy studies, featuring a module on historical and cultural context. ${ }^{22}$ How does acupuncture fit into the CAM context? Is it still traditional? The language and terminology referring to it often reflects a holistic, 'New Age' influence. Bringing history into the modern context would be most useful. Show how history fits into contemporary practice and its influences.

Volker Scheid: I want to just say that, you say Leamington has no history, of course they have a history, history is always there. No, I think it's really important. What this history is about, is about 'enabling' and thinking about where we are now, rather than teaching history as a science, or anything. I think that's what this has to be about, being critical.

Sylvia Schroer responded that she meant that there was no actual class on history when she was at Leamington.

Volker Scheid: Yes, but still there's a history (to the school).

${ }^{21}$ She refers to a town in Warwickshire, England, 'Royal Leamington Spa', where J. R. Worsley established his school of traditional Chinese acupuncture, also known as the 'Five Elements' acupuncture. See Eckman 1996.

${ }^{22}$ She refers to the Department of Complementary Therapies in the School of Integrated Health at the University of Westminster, England: http://www.wmin.ac.uk/ sih/page-85 
Marta Hanson: And it should be written up and submitted to Asian Medicine. (Laughter).

Will Morris stated that the physician's pulse watch in 1700s Europe featured some aspects similar to Chinese pulse diagnosis. He gleaned classical ideas about cycles and the circulation of ying $q i$ and wei qi. Looking at time cross-culturally is significant.

Vivienne Lo: I agree. And I think one way that comparison could be brought out, and it's something that actually there's not enough research on to articulate very clearly, but it is beginning, and that is the calendar, the calendar of ritual. The calendar, rather than religion, because religion has a particular, you know, religion takes us back into Daoism, Confucianism, Buddhism, etc., but the calendar unites all those things.

Marta Hanson: But then, what I think Will is asking us to make explicit is the concept of time as historicised, that there isn't an essential time, that it's a concept, and that it differs culturally. Making it concrete through the calendar, and actually answering Steven's question to ensure we don't forget the broader aspects of concepts of $q i$ in Chinese culture, would be worth doing.

Vivienne Lo: I mean, I think there is published research on astronomical phases and the circulation of $q i$, on the Five Agents and prognosis (i.e., Donald Harper) and the calendar and medicine in medieval times. But the relationship between divination, the almanacs and medicine gets very complicated, actually, more and more complicated, as you go along.

Marta Hanson: You have to have a specific example that's complex, a more general statement about it, and a lesson to be learned.

Felicity Moir suggested that schools may need to consciously promote 'confusion'. Many of the attendees here perceive they underwent poor training. It is a problem if the curriculum or the textbooks are too well organised, because it does not encourage the curiosity of the students. To say, 'I know there's something out there, and I've got to go and find it for myself.' She also referred to a view of time in which the past is in front of us because we can see it, while the future is behind us, because we have not yet seen it.

Marta Hanson: The Chinese terms are exactly reflective of that idea, seeing time as qiantian 'the day before yesterday' or the day in 'front of us', and houtian 'the day after tomorrow' or the day 'behind' us. The other way I like to consider time, at least with the students, is that there's always the 'ever present present'. There is no past or 
future, except how we imagine it in our own lives, philosophically. So that the clinical encounter is that moment when the past is integrated into how we conceive of a possible future, but there's always only ever the present.

Adam Margolis returned to Volker Scheid's claim that historical precedent is often irrelevant for biomedical physicians. He finds this controversial. An article appeared in the Journal of the Society for Integrative Oncology by Stephen Sagar, who has written a book on the integration of Chinese medicine into cancer therapy. ${ }^{23}$ In a rather short clinical article, there was at least a page on the history of western medical education. ${ }^{24}$ Adam expressed that it is important to be aware of both Chinese and western medical history.

Vivienne Lo: One of the problems around all of this is funding, and coming from the Wellcome Trust Centre for the History of Medicine, there is funding for western history, but they also, more and more, have comparative funding for the history of Asian medicine. But, it's all institutionally funded, which defines so much of who we are, and where we are, and what makes things possible.

Andy Pham: I'm a panelist this morning, and I was a panelist yesterday morning. I made a presentation from the student's point of view. Michael McCulloch is a clinician from the Bay Area, who is sort of a proponent of the tutorial model of education, but one thing he said is that sometimes the students have the most insight into how things should be, or how things should be taught. We should listen to what they say, what they feel, what their opinions are. And so, I believe that yesterday I spoke from the student's point of view when I said that the schools of TCM are lacking in a lot of ways; they leave a lot to be desired, at least here in the US, from what I've observed and from the schools that I've attended. And it may have seemed yesterday, when I spoke a lot about how powerfully biomedicine is integrated into the TCM universities in China, you may have gotten the impression that I may share that opinion, that biomedicine should equally be elevated to some kind of higher status in the TCM schools. I didn't really get to my conclusion, but in fact, I would conclude the exact opposite: I would say biomedicine should sort of be relegated, or, sort of lowered in status, and yet,

\footnotetext{
23 Sagar 2001.

24 Sagar 2006.
} 
history and philosophy should be brought up in status within the TCM schools here in the US. I say this, just listening to students and also my instructors say, 'I don't really care if you remember Wu Youke (1582-1652) or you know, Wu Jutong (1758-1836), I don't really care if you remember their names, it's just their ideas that I care about.' But, I argued that it is important to remember who they are, and something about how they thought. And I would say that Dr Scheid's book, when I was writing my manuscript, that was, I think, maybe the first book in English that, like he said, you got the sense, not just of who they are, their names, dates, and places, but literally, these were, sort of people who evolved. I remember reading about Qin Bowei, also Fang Yaozhong, and then Yue Meizhong as well in the chapter on 'Hegemonic Pluralism: Chinese Medicine in a Socialist State'. And we're just talking now about people from the 1950s, we're not even talking about the dynasties in the past. But if TCM is really from the 1950s, then I don't think it's ambitious to say, just to start to know some of these makers of TCM from the 1950s. Volker Scheid's book is a way to do that.

Another thing I would say is, I'm picking up from Amy Hanks' point in the very beginning when she said very few students come into the TCM schools with any background in history at all. Actually, there was an anthropology professor, Mei Zhan, who did ethnographic research at the American College of Traditional Chinese Medicine, where Ms Hanks is an instructor. She said that some of the students majored in the arts and humanities, and others majored in the natural sciences. I claim that being a student in the natural sciences is not relevant to then becoming a student of Chinese medicine. And I've told this to biochemistry majors I've met, chiropractors, massage therapists, physical therapists, that, you know, it really sort of biases your view of TCM when you come in and you don't think that history or philosophy are very important. So, if I could be involved in education, I would just rewrite all the prerequisites. (Laughter).

I mean, literally, I know that sounds very dangerous and that might offend some people, but the schools are literally puppets that jerk. You pull the string, and they will do what you want. So, if the State Board, all of a sudden, changes things and says, instead of 22 units of science prerequisites, which I said yesterday looks a lot like the prerequisites for entering biomedical school, it's just everything is on the scale of half, instead, I would have a semester of Asian history. 
Again, it's a semester, I'm not asking for a full year here. A semester of Asian history, a semester of Asian philosophy, and then Nigel Wiseman, who was at the Pacific Symposium six years ago, presented a long series of articles about language being 'the neglected key'. He went into much detail. He also spoke in Munich (August 2005 International Conference of the Society of East Asian Science, Technology, and Medicine) last year on 'The Western Reception of Chinese Medicine: Failure to accord history and culture their rightful place'. But, six years ago, he said language was the neglected key, and he suggested three ways to bring language into the TCM curriculum. I think this could be applied to history and philosophy. He said, one, is that we try to teach it in the TCM schools, ourselves. And Ms Hanks and other people here, I think, are attempting to do that. But, I don't think that's the case at the schools that I've attended, unless perhaps at Amy's school. I think it's very unrealistic to think that way. I don't think the instructors are in that position to teach Chinese history and philosophy. The second model he said, which maybe applies more to language and less to history and philosophy, is to be self taught, to somehow allow the students to teach themselves Chinese language, and then to administer some sort of competency exams, or exams where you could gain credit. Somehow, I think that that's also difficult when you talk about history and philosophy. But, the third model that he suggested, in the context of language, which I like a lot, for history and philosophy, is to come in with that background.

And so, ideally, if someone could have a four-year degree either in Asian Studies or East Asian Language and Literature, or something along these lines, that would be ideal. But, I'm not an idealist. In fact, yesterday, I said that there's a lot of idealism, but I'm more of a realist or an 'actualist'. So I say, instead of forcing people to have degrees in history and philosophy, make them take prerequisites. Be a 'pre-med' in TCM. But don't do it by taking biomedical prerequisites; make them historical, philosophical, and language prerequisites. That's a very controversial idea, but somehow I think it's realistic.

Brett Finch, a student at the Texas College of TCM in Austin, followed up on Andy's statements about the lack of depth and breadth in TCM history classes. Some classes compressed their presentation on history into one half day, for the entire term. A class on the TCM classics also took a clinical, rather than both clinical and his- 
torical, perspective. He thought that a historical teaching model should include not just the dates but also the social, political, and economic events at that time. These shaped why certain ideas were chosen, the philosophy underlying modalities, religious attitudes, etc. He recommended a full year, on both history and philosophy, in the TCM schools as required classes. However, currently teachers in such colleges teach to the test, the boards, and that's it.

Rey Tiquia brought up his reading of the Yishi sanzijing (Three Character Classic of Medical History) by Chen Zhiyuan, as a good example of how to write a succinct history of Chinese medicine through short poems. In only ten pages, it runs from the time of the Huangdi neijing (Inner Canon of the Yellow Emperor (first century BCE)) up to the Ming dynasty (1368-1644). It would be worth looking at.

Marta Hanson: That would be wonderful, a history book in the form of poetry. Actually, using the rhyming mnemonic, they use it for formulas, they use it to help memorise, complex analogies, it's a great example of making that history more easily remembered. Also perhaps valuable to teach how they remembered it in verse.

Stuart Watts, founder of the Academy of Oriental Medicine at Austin, presented himself as the 'devil' in the room. He helped set the state standards for TCM in New Mexico. The issues he sees as important are what does the profession want. The current situation is the outcome of what those people involved at the time wanted for TCM in this culture. Basic parameters are required, and 'teaching to the test' is a necessary part of that. Students need basic models for further development. But, everyone should keep bringing up these issues, as people are receptive.

Zev Rosenberg wanted to comment on Andy's assessment of the TCM schools. We do indeed have to look at the reality. The profession still lacks a professional teaching body as one finds in universities and colleges. A central problem is that most teachers are full-time practitioners and part-time instructors, facing an impossible situation of receiving no support for teaching structure, no tenure, low salaries, and no pension. Chinese medicine should be like academia and its educational model, but that is not the case. The field needs to look at the state of its education, but the student body also needs to improve. There is not enough discrimination in selecting students, who sometimes expect a 'massage school', but then see the required books and can't handle it. 
Marta Hanson: That's actually what I find so fascinating about the field; the diversity of people involved in it and their (different) positions. We actually have to end, but, I know Andy and Volker wanted to say something.

Volker Scheid: Just give me a minute, please, it will be about the final goal for your book.

Marta Hanson: I didn't say that it's my book or that I'm publishing anything. I'm facilitating a conversation about the project and the idea.

Volker Scheid: Our book, or whatever. Paul Unschuld is not here, but you know Paul Unschuld says something very important that I think we should think about. He says that Chinese medicine is a tradition that is essentially already dead, that it's just a dead piece of wood. And that dead piece of wood we can still use for many interesting purposes, but his argument is, as a tradition, it's dead. Now I don't know whether that's true or not. When I was in China, when I first studied Chinese medicine, I belonged to a group, and that's when I first got to know people like Ye Tianshi, as people, and the feeling I had being in that group was, it was something like when I was a bit younger, I was talking about pop music, when I was talking about the Beatles and the Rolling Stones and that kind of thing. And to me, the tradition that is alive is, for instance, modern music. You know, rock music, pop music, and the people who are in that tradition. They don't do history, they're not historians, but they all know about history, they know about the history of the Rolling Stones, the Beatles, and...

Marta Hanson: You mean that they quote from their predecessors in their own lyrics.

Volker Scheid: Just go on Wikipedia, and type in any group. What you'll find is the history of that group, where they come from, what they've done, what are their influences, and things like that. And I think if we, as involved in Chinese medicine, want to be alive as a tradition, then that's what we have to be. Whatever this book is going to be, if it can contribute to that, that would be, for me, the goal. And, if not, if students and teachers cannot be like that, that's the kind of conversation that I want to see, amongst all of us. You know, the same kind of conversation, the same kind of enthusiasm, everything that happens with artists, musicians, it could be like that. Marta Hanson: I think that's actually a poetic metaphor to end this conversation. So, thank you all so much for coming. (Applause). 


\section{Concluding Remarks}

Stephen Boyanton, MA: Religious Studies, University of Virginia (2004), Adjunct Professor, Humanities Discipline, San Diego Mesa College. Junior student of Chinese medicine at Pacific College of Oriental Medicine, San Diego.

From at least the Song dynasty onward, the ideal practitioner of the literate tradition of Chinese medicine was a scholar of both medical texts and the broader Chinese literary, artistic, and philosophical tradition. Although the content of their scholarship differs, the influential physicians of the late Qing and early twentieth century and the laozhongyi - older, senior physicians - of more modern times have generally continued this tradition through their insistence on a knowledge of the classical medical corpus and the importance of continuing to use Chinese medical categories and theory. The Chinese medical tradition differs fundamentally from biomedicine in its attitude toward tradition. While it would be inaccurate to say that Chinese medicine has maintained an unchanging tradition throughout its history, or that there is no notion of progress in the Chinese medical tradition, it is undeniable that a re-evaluation of the past has often served as inspiration and justification for new developments within the tradition.

Given the paucity, and frequently poor quality, of English translations and historical information regarding Chinese medicine, the English-speaking community of Chinese medical practitioners is cut off from the wellspring of its own tradition and even from a correct understanding of the nature of that tradition, its current status and historical development. This cannot fail to have real, clinical consequences and impede the utility of Chinese medicine in the Englishspeaking world. As an academic researching the history of Chinese medicine and as a future practitioner, it is my sincere hope that scholarship and practice will be reunited in the English-speaking world, allowing the full scope and power of Chinese medicine to benefit the health of those outside of its traditional homelands.

Brenda Loew, LAc: Practitioner of Japanese-style meridian therapy acupuncture as well as a teacher of Japanese acupuncture for the Toyohari Association and of continuing educational classes at Bastyr University and Wu Hsing Tao School of Acupuncture in Seattle.

The Toyohari model is an interesting one as it is based on the classics such as the Nan Fing but tests the validity of classical theories 
through group study and hands-on practice and has made adaptations to classical theory. If the theories can be applied to groups in a fashion that has a useful clinical outcome, such theories are skillful and worth 'preserving'. I am particularly interested in the role of intention/consciousness in becoming an acupuncturist or any type of healer. How can the quality of mind/being/consciousness be communicated/taught to students? I think inner cultivation is paramount in becoming a healer (or even in becoming truly 'human'). Aside from personal and even group study, observation of mentors who hold such a quality of being is also important in the training of a healer.

\section{Shelley Ochs}

I think practitioners have two goals when they study the history of medical ideas and techniques in China: incorporating new methods into our work and expanding our understanding of how health and disease can be conceptualised. Works that emphasise the analysis of medical thought and practice in a thematic, rather than a strictly chronological, manner may best serve those ends. History changes our view of what 'the tradition' is, and, necessarily, our place in it. If the heterogeneity of medicine in China was widely known and accepted by practitioners in the US, the educational and professional credentialing systems would be reformed in order to incorporate a more pluralistic framework for studying and practising Chinese medicine.

\section{Andy Pham}

Andy Ellis has dichotomised two types of clinicians: those who are interested in historical precedence and those who are not. In the interest of preserving it as a cultural tradition, Chinese medicine would benefit from an increased representation of the former. Bensky contends that history recognises the diversity of approaches and challenges the limitations of standardisation. Scheid asserts that 'Chinese medicine is history' and should be practised historically rather than scientifically, as though one were within the tradition rather than distant from it, in a typically academic sense. While historical knowledge has been shown to be especially relevant to the application of single herbs, ${ }^{2.5}$ this is just as true for formulas, acupuncture points, and needling styles, as Scheid states. Bensky and Scheid agree that

\footnotetext{
${ }^{25}$ Zheng 2002.
} 
history must be clinically relevant; to achieve this is to engage with the tradition itself, a theme they have explicated before. ${ }^{26}$

It is not a coincidence that the panelists are also well versed in reading and translating Chinese. While it is often lamented that a background in the language is usually missing among clinicians, the same could be said of the neglect dealt history in clinical training. A background in history is perhaps an intermediate compromise in approaching Chinese medicine as a cultural tradition, before the acquisition of linguistic capacity. The most promising way to develop historically minded clinicians is to broaden their exposure to it as students. In addition to the sources, curricula, and teaching approaches, the different learning styles of students and how they relate to history should be taken into account.

Jane Wilson, MBAcG: Senior Lecturer in the Department of Complementary Therapies, School of Integrated Health, University of Westminster; also has her own clinic in London.

I would like to support the statements that reflect the need to approach history from a perspective that enhances the students' and clinicians' ability to place themselves within this history. On the question of specifics, I would love to see more work on points and prescriptions, specifically the classification of the points and the meanings behind these classifications. Then, moving from the individual points onto the construction of points' prescriptions, how points work together, and how they have been used through history. Looking also at treatment times for needle insertions; techniques; same points repeated or new points each time, frequency of treatments; flexibility of point choice according to external conditions (seasons, climate, time of day); order in which to needle points, and the whole treatment scene. Whilst I see quite a lot of work being undertaken in the study of herbal prescriptions, I do not see the same time and effort being given to the history of point prescriptions.

Teachers do need to study more Chinese, learn more history, and there should be far greater availability for true Master's courses in Chinese Medicine. But most teachers, despite working to textbooks and assessment schedules, do try to embody the ethos of confusion, adopting holistic- or phenomenologically-oriented ways of thinking. Teachers teach that these facts are not fixed, that there is a choice

${ }^{26}$ Scheid and Bensky 2000. 
of utilising the different approaches in clinical practice. The students have to become individual clinicians and take responsibility for their own choices, to reflect the philosophy, context, and meanings behind what they do, and accept, finally, that clinical practice is not easy.

\section{References}

Bensky, D. and R. Barolet 1990, Chinese Herbal Medicine: Formulas and strategies, Seattle: Eastland Press.

Bynum, W. and H. Bynum (eds.) 2007, Dictionary of Medical Biography, 5 vols, Westport, Conn.: Greenwood Press.

Deadman, P. 1985, 'Acupuncture in the West-A discussion between Ted Kaptchuk, Giovanni Maciocia, Felicity Moir and Peter Deadman', Joumal of Chinese Medicine, 17: 1-14.

Emad, M. 2003, 'Needling as Translation: An anthropologist responds to TSCA's Needling Colloquium', Clinical Acupuncture and Oriental Medicine, 4, 4: 164-8.

Furth, C. 1999, A Flourishing Yin: Gender in China's medical history, 960-1665, Berkeley: University of California Press.

Lo, V. and C. Cullen (eds.) 2005, Medieval Chinese Medicine: The Dunhuang medical manuscripts, London/New York: RoutledgeCurzon.

Payer, L. 1996 [1986], Medicine and Culture: Varieties of treatment in the United States, England, West Germany and France, New York: Henry Holt and Company. Original published in New York: Penguin Books, 1986.

Ren Yingqiu 任應秋, 1980, Zhongyi ge jia xueshuo 中醫各家學說 (Doctrines of the Lineages of Leaming of Chinese Medicine), Shanghai: Shanghai kexue jishu chubanshe.

Sagar, S. M. 2001, Restored Harmony: An evidence-based approach for integrating Traditional Chinese Medicine into Complementary Cancer Care, Hamilton, Ontario, Canada: Dreaming Dragonfly Communications.

-, 2006 , 'Integrative Oncology in North America', Joumal of the Society for Integrative Oncology, 4, 1: 27-39.

Scheid, V. 2002, Chinese Medicine in Contemporary China: Plurality and Synthesis, Durham/ London: Duke University Press.

Scheid, V. and D. Bensky 2000, 'Pluralism or Plurality: More reflections on "Medicine as Signification"', European Journal of Oriental Medicine, 3, 2: 63-4.

Seem, W., C. Cassidy, H. M. Langevin, Lixing Lao, and M. Seem 2003, 'Getting to the Point: A forum for master practitioners, researchers and educators', Clinical Acupuncture and Oriental Medicine, 4,4: 148-63.

Wallace, A. 1996, Choosing Reality: A Buddhist view of physics and the mind, Ithaca, New York: Snow Lion Publications.

Wilms, S. 2006, Essential Thousand-Gold Formulary for Emergencies: Women's Formulas, Taos, New Mexico: Paradigm Publications.

Zheng Jinsheng 2002, 'Historical Research in Chinese Medicine: The relationship between historical research and clinical use of medicinals', Clinical Acupuncture and Oriental Medicine, 3,3: 129-37. 


\title{
Bibliography of Historical Surveys of Chinese Medicine in English
}

\author{
(With Tables of Contents)
}

Eckman, P. 1996, In the Footsteps of the Yellow Emperor: Tracing the history of traditional acupuncture, San Francisco: Cypress Book Company. 1. The Circle. 2. TCM and LM (Leamington Acupuncture). 3. Legendary Lessons in Virtue. 3. From Mythology to Medicine: A History of TOM (Traditional Oriental Medicine). 4. 'History as Mystery' Traditional Acupuncture's Journey to the West.

Felt, R. L. and S. J. Birch 1999, Understanding Acupuncture, New York: Churchill Livingstone. Section 1. What Acupuncture Is. 1. History, 2. Acculturation and Re-acculturation of Acupuncture. 3. The Theoretical Basis of Acupuncture. 4. How Acupuncture Works. Section 2. How Acupuncture is Practised. 5. What does Acupuncture Treat? 6. Diagnosis and Patient Assessment. 7. Treatment. 8. Conclusion and Strategies for the Future.

Furth, C. 1999, A Flourishing Yin: Gender in China's medical history, 960-1665, Berkeley: University of California Press. 1. Yellow Emperor's Body. 2. Fuke in Song. 3. Gestation and Birth in Song. 4. Rethinking Fuke in Ming. 5. Fuke in Late Ming Medical Culture. 6. Ming Bodies of Generation and Longevity. 7. Cheng Maoxian in Yangzhou. 8. Ming Women as Healing Experts.

Ho, Ping-Yoke, F. P. Lisowski 1998, A Brief History of Chinese Medicine and Its Influence, Singapore: World Scientific. 1. Concepts and History. 2. Areas influenced by Chinese thought. 3. Medicine in Japan. 4. Medicine in the Islamic World.

Hoizey, D. and M.-J. Hoizey 1993, A History of Chinese Medicine, Edinburgh, Scotland: Edinburgh University Press. Translated from French by P. Bailey. Original by Editions Payot, 1988. 1. From Mythology to History. 2. From Western Zhou to end of Warring States. 3. From the First Emperor to the Fall of the Han Dynasty. 4. From the Three Kingdoms to the Northern and Southern Dynasties. 5. The Sui and Tang Empires. 6. From the Northern to Southern Song. 7. The Jin and Yuan. 8. The Ming. 9. The Qing from Manchu Invasion to the First Opium War. 10. The Qing, 1842-1911. 11. From the 1911 Revolution to the Establishment of the PRC. 12. Mao Zedong's China.

Hsiung, Ping-chen 2005, $A$ Tender Voyage: Children and Childhood in Late Imperial China, Stanford: Stanford University Press. Introduction: Children and Childhood in Traditional China. I. Physical Conditions. II. Social Life. III. Multiplicity.

Huan, Zhang Yu and K. Rose 1999, Who Can Ride the Dragon?, Brookline, Mass.: Paradigm Publications. 1. Language of Chinese Medicine. 2. Folk Beliefs, Myths, and Customs. 3. Philosophy and Religion. 4. Literary Tradition. 5. Chinese Scientific Tradition. 6. Sexual Culture, Longevity, and Immortality. 7. Key Terms of Chinese Medicine.

Huard, P. and Ming Wong 1986, Chinese Medicine, New York: McGraw-Hill. Translated from French by B. Fielding. 1. The evolution of Chinese medicine. 2. Chinese medicine and the medicine of other Asiatic countries. 3. Medicine in China and Europe. 4. Western medicine in modern China. 5. Traditional medicine in modern China.

Lo, V. 2005a, '2,000 Years of Chinese Acupuncture, Part I', Asian Medicine, 1.1: 222-8.

2005b, '2,000 Years of Chinese Acupuncture, Part 2', Asian Medicine, 1.2: 494-504.

Lu Gwei-djen and J. Needham 2002 [1980], Celestial Lancets: A history and rationale of acupuncture and moxa, London: RoutledgeCurzon. With a new Foreword by V. Lo. Original published in Cambridge, England: Cambridge University Press. 
1. Introduction. 2. The ching-lo system and its classical theory. 3. Historical growth of the system. 4. Moxibustion. 5. Therapy and analgesia. 6. Influences on other cultures. 7. The lore of vital spots. 8. Conclusions.

Porkert, M. with Dr C. Ullmann 1988, Chinese Medicine as a Scientific System: Its history, philosophy, and practice, and how it fits with the medicine of the west, New York: Henry Holt and Company. Translated and adapted from German by M. Howson. Original published in Dusseldorf and Vienna: Econ Verlag GmbH, 1982. 1. Chinese and Western Medicine. 2. Fundamentals. 3. Orbisiconography. 4. Sinarteriology. 5. Diagnosis. 6, Therapy. 7. The History of Chinese Medicine. 8. The Current Situation.

Unschuld, P. 1985, Medicine in China: A history of ideas, Berkeley: University of California Press. 1. Illness and Healing in Shang Culture. 2. The Chou Period and Demonic Medicine. 3. Unification of the Empire, Confucianism, and the Medicine of Systematic Correspondence. 4. Taoism and Pragmatic Therapy. 5. Religious Healing: Foundation of Theocratic Rule. 6. Buddhism and Indian Medicine. 7. Sung Neo-Confucianism and Medical Thought. 8. Medical Thought during the Ming and Ch'ing: Individual in Search of Reality. 9. Medicine in Twentiethcentury China. Appendix primary texts in translation.

1986, Medicine in China: A history of pharmaceutics, Berkeley: University of California Press. 1. Introduction. 2. Shen-nung. Pen-ts'ao, origins of pharmaceutical literature. 3. Comprehensive contents. 4. Chin-Yuan Epoch. 5. Two Sixteenthcentury works. 6. Eclectic tradition. 7. Han-hsüeh tradition. 8. Specialized contents. 9. Twentieth-century pharmacopoeias.

1998, Chinese Medicine, Brookline, Mass.: Paradigm Publications. Translated from the German by N. Wiseman. Original published in München: C. H. Beck, 1997. 1. Formative phase. 2. Doctrine of the Five Periods and the Six Qi. 3. Ophthalmology. 4. Uses of Drugs and Pharmacology. 5. Chinese Medicine in China in the Modern Era and Present. 6. The Long March West.

2000, Medicine in China: Historical artifacts and images, Munich: Prestel. Original in German published in München: Prestel, 1995. 1. The History of Medicine in China: Overview. 2. Literature of Traditional Chinese Medicine and Pharmaceutics. 3. The Chinese Pharmacy. 4. The Chinese Physician, His Patients, and His Instruments. 5. Medicine, Healing, and Popular Religion. 6. Chinese Medicine in Art and Literature.

Wong, K. Chimin and Wu Lien-the 1936, History of Chinese Medicine, Shanghai: National Quarantine Service. Vol. 1. Evolution and development of the indigenous art: 1. Ancient or Legendary Period (2697-1122). 2. Historical or Golden Period (1121BC-960 AD). 3. Mediaeval or Controversial Period (961-1800). 4. Modern or Transitional Period (1801-1936); Vol. 2 Introduction and development of Modern medicine in China: 1. Before AD 1600. 2. Between AD 1600-1800. 3. Jennerian Vaccination. 4. 1820-1842. 5. Autumn 1842-1855. 6. 1856-1865. 7. 1866-1879. 8. 1880-1885. 9. 1886-1893. 10. 1894-1899. 11. 1900-1910. 12. 1911-1920. 13. 1921-1927. 14. 1928-1936. 15. General survey and outlook. Chronological Table. 